\title{
ARTÍCULO
}

\section{La Constitución "social" supranacional como ficción: lecciones de Weimar a propósito de las diferencias entre la falta y la imposibilidad metafísica de cumplimiento constitucional•}

\section{The supranational "social" constitution as fiction: Weimar's lessons on the differences between the lack and the metaphysical impossibility of constitutional compliance}

\author{
Ainhoa Lasa López \\ Departamento de Derecho Público y Ciencia Histórico-Jurídicas y del Pensamiento Político \\ Universidad del País Vasco (UPV/EHU)
}

Fecha de recepción 25/05/2020 | De aceptación: 29/09/2020 | De publicación: 28/12/2020

\section{RESUMEN.}

En esta reflexión trataremos de dar respuesta a dos interrogantes presentes en el debate generado tras la crisis de 2010-2012 del proyecto europeo. Por una parte, ¿es posible revertir la centralidad incondicionada del mercado único sin romper los Tratados? Por otra parte, ¿pueden los Estados miembros neutralizar esta centralidad a través de la Constitución de la forma de Estado social? Para ello, recuperaremos, con matices, la dialéctica metodológica del periodo de entreguerras de Weimar sobre la política, el poder, y su relación con lo jurídico.

\section{PALABRAS CLAVE.}

integración constitucional, conflicto social, integración económica, integración social.

\section{ABSTRACT.}

In this reflection, we will try to respond to two questions present in the debate generated after the crisis of 20102012 of the European project. On the one hand, is it possible to reverse the unconditional centrality of the single market without breaking the Treaties? On the other hand, can the Member States neutralise this centrality through the constitution of the social state form? For this purpose, we will recover, with nuances, the methodological dialectic of the inter-war period in Weimar on politics, power and their relationship with the constitutional law. KEY WORDS.

constitutional integration, social conflict, economic integration, social integration

\footnotetext{
- El presente artículo es una versión mejorada y ampliada de la comunicación presentada bajo el título "Why an "emergency social and economic democracy" at European level is an unpostponable constitutional need: lessons of Weimar", al Workshop "Weimar Moments. Constitutionalising Mass Democracy in Germany, Italy, Spain and Beyond, celebrado en Madrid, los días 13 a 15 de noviembre de 2019. Paralelamente, la contribución se ha desarrollado en el marco del proyecto de investigación, Estado Económico, Capitalismo financiarizado, Constitución, Gobernanza (DER 2017-84562-P). IP: Miguel Ángel García Herrera.
} 
Sumario: 1. Aproximaciones preliminares. 2. La Constitución de Weimar como Constitución de la integración: una concepción sustancial del Derecho. 3. El constitucionalismo en la crisis del Estado social: la depuración de la normatividad constitucional y su funcionalidad al nuevo orden de mercado europeo. 4. La relación de subordinación del dispositivo social supranacional con la decisión de sistema del orden europeo y sus efectos. 4.1. La expulsión de lo social del espacio constitucional de la Unión y su confinamiento al ámbito legislativo. 4. 2. La adhesión de las instituciones supranacionales a la decisión de sistema: especial referencia a los contenidos político-propositivos de la fase postcrisis del euro (2014-2019) y de las elecciones a la IX Legislatura. 5. A modo de conclusión: del interregno de la centralidad del mercado a la transformación, como reordenación, de las relaciones política-economía. 6. Referencias bibliográficas.

\section{Aproximaciones prelimimares}

Es lugar común, en las reflexiones que se suceden sobre la gestión de la crisis del euro de 2010$2012^{1}$, contextualizar esta crisis más allá de su afectación a la gobernanza de la economía y la moneda (Kjaer y Olsen, 2016:xii). En este sentido, las lecturas mayoritarias sobre las reformas acometidas para reforzar la Unión Económica y Monetaria (UEM), concluyen señalando que esa crisis y su gestión ha terminado por generar, a su vez, una crisis de legitimación del propio proyecto europeo. Las causas, argumentan, se sitúan en los déficits jurídicos y políticos presentes en los procesos de adopción de algunas de las nuevas normas que integran el marco de la UEM renovada (Joerges, 2016: 149-150). Con respecto a las insuficiencias jurídicas, porque tan solo algunas de las medidas legislativas se han adoptado siguiendo los cauces jurídico-procedimentales habilitados al efecto por el Derecho de la Unión (DUE) ${ }^{2}$, mientras que el grueso de las mismas se han adoptado a través del recurso al Derecho internacional ajeno al orden de la Unión ${ }^{3}$. Esta última tipología de medidas carece de los mecanismos de garantía jurisdiccional y control político habilitados al efecto por el DUE. Además, a esta diversa naturaleza jurídica habría que añadir que los nuevos mecanismo y procedimientos basan su legitimidad política en una democracia no representativa que sustituye, en vez de complementar, a los tradicionales principios de representación (Nicolaidis, 2019: 104-105). La legitimidad económica sería el sostén de este nuevo tipo de democracia monoclase, en tanto que fundamentada en un único interés (el del mercado único),

\footnotetext{
${ }^{1}$ El origen de la crisis del euro se sitúa en factores externos e internos a la Unión Económica y Monetaria. Con relación a los factores externos, la espiral creciente de sobrevaloración de los precios de la vivienda y las restricciones del mercado de créditos, materializó la importación de los efectos de la liquidación del banco estadounidense Lehman Brothers al sector bancario de la zona euro, debido a la intensa integración del mercado financiero europeo con el estadounidense. Respecto a los factores internos, la ocultación del nivel real de deuda y déficit de la República Helénica, confirmó la debilidad de la UEM para garantizar el control de los déficits públicos excesivos. Los mercados financieros temían el impago público y privado porque algunos de los préstamos habían sido financiados por bancos privados de otros países europeos, principalmente, alemanes, franceses y españoles. El temor al impago se extendió a otros países europeos (Chipre, Chipre, Irlanda, Italia y Portugal), generando el efecto dominó de los llamados préstamos dudosos o de reembolso imposible. Montani (2016: 126-128).

${ }^{2}$ En particular, las medidas legislativas relativas a reforzar la gobernanza económica de la Unión Europea y de la zona euro.

${ }^{3}$ Es el caso del Tratado de Estabilidad, Coordinación y Gobernanza en la Unión Económica y Monetaria de 2012, también denominado Pacto Fiscal Europeo.
} 
que contrasta con la democracia interiorizada por los textos fundamentales de los países miembros, basada en el pluralismo que acompaña a la multiplicidad de preferencias políticas y marcos discusivos. Por el contrario, la legitimidad económica reconduce el espacio de decisión a un ámbito sustraído al debate de, y entre, opciones políticas diversas. El único ámbito es el de la pervivencia de la centralidad incondicionada del mercado, aún a costa del factor democrático (Sacriste y Vauchez, 2019: 35). La opacidad y la falta de responsabilidad que nutre este agujero negro democrático se materializa, en palabras de Castro-Conde y Bouza (2019: 23), en una disociación entre políticas sin política en las instituciones europeas, frente a una política sin políticas a nivel nacional. Por lo tanto, la crisis de legitimidad supranacional también ha dejado sentir sus efectos en las democracias de los países miembros. De hecho, el fortalecimiento del sistema del euro ha alterado las bases fundacionales constitucionales de la Unión y los Estados miembros (EEMM), especialmente en lo referente a las sinergias de la cohesión y la solidaridad entre los países miembros y la Unión.

Esta gran transformación en las instituciones jurídicas, en los ordenamientos y en las formas de poder, son efectos generados por el cambio de paradigma económico en los mecanismos de la gobernanza de la UEM. Este cambio se manifiesta en la transición hacia una Unión de ajustes nacionales, paralela al debilitamiento del compromiso de solidaridad interterritorial (Starita, 2017: 12-19). La subordinación de los programas de ayuda y rescate a los países de la zona del euro al estricto cumplimiento de las normas fiscales introducidas durante la gestión de la crisis, ilustran la hegemonía de la estabilidad de precios y el equilibrio presupuestario, en detrimento del papel funcional y político clave de las políticas de solidaridad y de cohesión social presente en los Tratados fundacionales.

El malestar por la integración a través de la crisis del euro agudizó, en la fase postcrisis, las posturas que abogaban por recuperar espacios para la convergencia social, si bien desde planteamientos sustancialmente divergentes. Por una parte, quienes situaban esta convergencia en el espacio supranacional a través de una Europa más social y, por ello, más política (Priewe, 2019). Por otra parte, los análisis de las debilidades del espacio europeo para garantizar la cohesión socio-económica, que reconducen al espacio nacional el ámbito preferente para la realización del desarrollo social. El argumento central de estos últimos es que, la renacionalización de las políticas sociales supranacionales, permitiría a los países el desarrollo de estas políticas conforme a unos parámetros constitucionales, los adscritos al Estado social, que desvinculan la viabilidad de lo social a su compatibilidad con las 
necesidades e intereses del mercado. De tal forma que, solo trasladando la solidaridad y la cohesión social al espacio de la política estatal, es posible desvincular la política del mercado y, por ello, preservar los sistemas de bienestar social nacional (Demertzis, Pisani-Ferry, Sapir, Wieser y Wolff, 2018:3). Prueba de ello, es que lo procesos de decisión del sistema del euro atribuyen a los parlamentos nacionales un papel deliberativo a través de la conferencia interparlamentaria, que es ajena al ejercicio de las funciones del debate político, al control de los órganos intergubernamentales y a la representación de la ciudadanía. El espacio estatal actuaría esterilizando los condicionantes de la legitimidad económica de la UEM renovada, por su facultad para legitimar un orden de signo distinto que conecta la política (nacional) con las políticas (económicas y sociales), esto es, el conflicto social y político (Allemand, 2017: 96).

Sin embargo, entendemos que lo paradójico de tales demandas es que hace décadas que la Constitución de la forma de Estado social se convirtió en una constitución inerme, entendiendo por tal aquella constitución desprovista de los principios estructurales que la dotan de identidad como Constitución de la forma de Estado social. Cuestión distinta es que se defienda la pervivencia del Estado social desde un relativismo de sus bases materiales (el conflicto social) que desvirtúa, precisamente, la normatividad material que prescribe a esta forma de Estado (García Herrera, 2015: 53-58). El inicio de la crisis del Estado social en la década de los 60, y su consolidación en los años 80 del siglo pasado, propicia una revisión metodológica en la aproximación a esta forma de Estado que consiste en disolver sus contenidos constitucionales en el ámbito de la disposición contingente o política constitucional. La corrupción de la Constitución del Estado social, como dice de Cabo (1997: 301), consiste en reducir la constitución a un conjunto de valores plurales que, desconectados de la forma de Estado, permiten emplear el dispositivo constitucional no ya para fines distintos, sino para fines contrarios a los previstos. La constante disposición política de la constitución permite la redefinición no solo de sus contenidos, sino de la unidad (pacto capital-trabajo) que dota de sentido a la constitución en su conjunto como proyecto de integración. Una aproximación metodológica que, como hemos advertido, coincide con el momento de crisis del constitucionalismo social y con el surgimiento de un nuevo orden de articulación de las relaciones política y económica que se confronta abiertamente con el Estado social.

Este nuevo orden encuentra en el proyecto de integración europeo el paradigma de su realización. Por lo tanto, si de acuerdo con nuestra tesis existe una contradicción entre modelos, Estado social-Unión Europea, lógicamente, en el primero de los planteamientos que propone una suerte de socialización del 
DUE, no comprendemos cómo puede trasladarse al espacio supranacional un dispositivo que asuma las funciones de intervencionismo público en el ámbito de las relaciones económicas y la corrección del mercado en la distribución de la riqueza, sin la ruptura de la actual decisión de sistema del orden europeo. En sintonía con las consideraciones brevemente expuestas, consideramos que es oportuno recuperar en esta sede la confrontación metodológica en la aproximación a la Constitución de Weimar, en base a la forma o a criterios materiales vinculados con la realidad, planteada en el periodo de entreguerras (Álvarez, 2011: 446, 450-451).

Por una parte, quienes mantuvieron una posición metodológica que separaba el ámbito jurídico del real, desterrando los elementos no directamente normativos, donde destacan las aportaciones de Jellinek (1978: 9-13). La importancia de considerar sus reflexiones radica en que, sus construcciones jurídicas funcionales a las necesidades del Estado liberal, no son practicables en el marco de la construcción de un nuevo orden político-jurídico que ya no puede conferir al Estado una posición externa respecto a la sociedad y a su regulación.

Por otra parte, también es obligado destacar a quienes, como Heller (1985: 283-285) o Schmidt (1982:137), optaron por una revisión metodológica del formalismo y se adentraron en el análisis de nuevas exigencias metodológicas que obligaban a redescubrir el Estado, la política y el poder, y su relación con lo jurídico. Para estos, Weimar supuso una superación de la separación Estado-sociedad. La definición del fenómeno jurídico desde la interiorización de la política y la contradicción del sistema normativo. La deconstrucción del mito liberal de la coherencia-unidad lógica, y su sustitución por la politización de las distintas visiones que acompañaron la gestación del texto fundamental. La nueva forma de Estado social exigía una nueva legitimación normativa material, donde el centro se sitúa en el papel integrador que está llamado a desempeñar la Constitución.

Esta distinción es relevante a los efectos que aquí interesan. En primer lugar, porque nos permite aproximarnos al germen de la construcción del Estado social desde perspectivas jurídico-metodológicas distintas que se reproducirán, con algunos matices, en los debates de los años 80 del siglo pasado sobre el Estado social de la crisis. Máxime, si partimos de la premisa de que la comprensión de las relaciones que interactúan entre las dimensiones política, económica y financiera de la sociedad, junto a la composición de sus potenciales conflictos a través de instrumentos de naturaleza jurídico-constitucional, 
representan el punto de encuentro entre el proceso constituyente weimariano y los textos fundamentales de la segunda postguerra mundial. En segundo lugar, porque al abordar las causas que condujeron a la Constitución de 1919 a su inactuación, con especial referencia a la crisis económica que experimentó Alemania de 1929 a 1933, podemos rastrear si algunas de ellas se reiteran en la crisis sistémica del Estado social de los años 80. En tercer lugar, y continuando con el paralelismo con la experiencia weimariana, porque es pertinente analizar en qué momento la falta de aplicación cedió el paso al agotamiento de la Constitución de Weimar y las Constituciones sociales de la postguerra. Por último, y centrándonos en el espacio europeo, porque cabe plantearse si son rastreables, en el momento de crisis experimentada en la UEM, las señales de agotamiento que acompañaron a los textos fundamentales del Estado social, y que pondrían en evidencia la falta de capacidad del Derecho originario europeo (los Tratados) para ordenar la actual evolución política y social supranacional.

\section{La Constitución de Weimar como Constitución de la integración: una concepción sustancial del} Derecho

Aunque las referencias al proceso constituyente weimariano están condicionadas por el ambiente en el que se desenvolvió la Constitución, las fuerzas sociales que promovieron su adopción y los acontecimientos que cercenaron su efectiva vigencia e implementación, no podemos decir que sus causas materiales (componente ambiental y social) y aspectos formales (mecanismos que conformaron su modelo constitucional), sean ajenos a la experiencia del constitucionalismo social de la segunda postguerra mundial. En particular, las aportaciones de tal proceso constituyente para integrar en el plano constitucional a un constitucionalismo de nuevo signo, superador de unas estructuras de ordenación social ancladas en la racionalidad del principio de separación economía-política del Estado liberal (Runciman, 2016:8).

En paralelo a la ruptura del texto fundamental de 1919 con la forma de Estado liberal, se produjo una revisión metodológica con relación a las funciones requeridas por el derecho público. La realidad política, como sostuvieron algunos autores, entre otros, Heller, requería conciliar el dato institucional con las dinámicas sociales (1992: 19-39). El derecho público debía por tanto favorecer la integración de la pluralidad de sujetos sociales en el Estado. El objeto del Derecho ya no podía basarse en la exclusión de los elementos metajurídicos. La ruptura del Estado liberal, que articulaba las relaciones políticas en 
clave de exclusión, y su sustitución por una nueva forma de organización política e institucional basada en la integración, exigía revisar el normativismo puro que separaba la norma de la realidad.

A pesar de ello, en otras interpretaciones de la Constitución de Weimar pervivió una metodología normativista que predicaba una construcción jurídica del Estado de Derecho desvinculada de las nuevas relaciones entre sociedad y política, siendo uno de sus máximos exponentes Jellinek. Desde esta teorización, la aproximación constitucional actúa desde la base de una teoría social del Estado en la que, sin embargo, no hay una síntesis entre política y derecho (Jellinek, 1978: 9-13). Más bien, se trata de compartimentos estancos, el estado y el derecho que, en todo caso, le sirven al autor como base de un razonamiento en términos estrictamente jurídicos. En este planteamiento, aunque puede adivinarse una consciencia de la debilidad de adoptar un enfoque centrado exclusivamente en la actividad del Estado como pura relación jurídica, se obvian las novedades normativas introducidas por la forma de Estado social. Significativa, al respecto, es la frase con la que concluye su análisis del ulterior desarrollo de la constitución de Weimar, "A diferencia de su predecesora, ha despertado, (...) el interés por problemas que tienen que ver con el derecho y la política constitucional” (Jellinek, 2019:66). La Constitución social a la que se reconduce la política social no se identifica con el Estado de Derecho y el ordenamiento jurídico. La primera se reconduce al espacio de lo disponible, legalidad ordinaria, los segundos al espacio de lo jurídico. De modo que el dispositivo social de Weimar dependería para su concreción de la relación de fuerzas políticas, al margen de cualquier límite que derive de la Constitución. Los límites a la composición del conflicto se desplazan de la Constitución a la contienda política sin ningún tipo de conexión con la forma de Estado social.

Frente a esta reflexión, para otros planteamientos las incorporaciones realizadas por el Estado social demandan una interpretación de la Constitución de 1919 donde la ruptura del Estado liberal y las incorporaciones que realiza el Estado social asignan una nueva función al texto fundamental, articulada en torno a la integración constitucional del conflicto social. Función que ya no se dirige a preservar las esferas sociales de la intervención estatal, sino que, al contrario, la constitución contribuye en la definición de las necesidades del desarrollo social (Car, 2019:395). No hay exclusión entre el derecho y la política sino una coincidencia que conecta en la Constitución la realidad con la norma y la norma con la realidad. Este enfoque implica que desde la propia constitución se va a reconocer un espacio disponible para el conflicto social. Pero, en ningún caso, este espacio disponible puede desatender la función de 
integración constitucionalizada hasta hacerla irreconocible. La función integradora tiene naturaleza constitucional, no política, porque en sus límites define las reglas del conflicto y los mecanismos para su composición. La naturaleza de compromiso de Weimar expresa el acuerdo existente sobre las reglas de coexistencia de una comunidad política basadas en la organización de una nueva realidad social y las políticas que derivan de ella.

La teoría de la integración se vinculará directamente a la integración del conflicto social en las tesis de Heller, para el que las transformaciones en el ámbito del trabajo y la economía demandan una idea material del Estado (1992: 19-39). Idea material que consiste en las nuevas funciones estatales, fundamentalmente intervencionismo estatal como mecanismo de actuación sobre el conflicto que ahora se traslada al Estado juridificándose. Desde esta óptica, la articulación política del Estado social interiorizaba el modelo social a construir basado en una determinada concepción del Estado, de la sociedad y de sus relaciones. Así, dirá Thornhill (2016: 95-96), el núcleo de la Constitución de Weimar era la idea de una nación inclusiva, basada en los derechos materiales colectivos garantizados a través de un cuerpo sistemático de legislación laboral donde el trabajo organizado desempeñaba un papel integrador, tanto en la legislación, como en los procesos de inclusión nacional en curso.

La función integradora del Trabajo, que se colocaba en una relación inmediata con la construcción nacional, implicaba que la fuerza de trabajo fuera considerada como parte fundamental de la idea material del Estado-nación. El constitucionalismo social emergente definía, por tanto, la relación funcional entre la nueva forma de Estado social y su vinculación a la fuerza integradora del Trabajo, que devenía sujeto político, junto con el capital, con competencia para participar en la regulación de la ordenación de la vida económica (Maestro Buelga, 2002: 25-39). El significado de un nuevo Estado que se contrapone al Estado liberal, articulado en torno a tres principios de naturaleza programática, contemplados en la segunda parte del texto fundamental y que reflejaban los principios socialistas del sistema: la subordinación de la actividad de los individuos socialmente relevantes a finalidades de interés colectivo, la noción sustancial de igualdad, y la subordinación de la actividad de los individuos socialmente relevantes a finalidades de interés colectivo (Mortati, 1972:333).

Las referencias al Trabajo, como garante del nuevo sistema económico, tuvieron en la doctrina iuslaboralista weimariana a su máximo exponente. Destacan, al respecto, las formulaciones en torno al 
concepto de democracia colectiva de Neumann (1987: 38-42), como componente dinámico de la democracia política con perfiles económicos y sociales que se nutren, a su vez, de las categorías organizativas políticas y jurídicas, la democracia económica, y del sistema de Consejos elaboradas por Sinzheimer (1982: 47-49). A través de la estructura de los consejos como instrumentos de participación de los trabajadores en los procedimientos de decisión económica, se actuaba la función de subjetivización del trabajo. De esta manera, el trabajo no se circunscribía al sector normativo relativo a las relaciones laborales, sino que era comprensivo también de elementos reales económicos y políticos. La constitución económica y la democracia económica inherente para su implementación complementaban, a través de su integración, a la constitución política y la democracia política (Dukes, 2014: 17-22). De forma tal que, la integración del conflicto capital-trabajo en la Constitución, implicaba su reconducción a términos integrables y componibles dentro de la acción del Estado.

Precisamente, en la limitación del poder empresarial, la participación en la dirección de la economía y el reconocimiento del nuevo sujeto colectivo representado por el trabajo, se configuraban como los ejes de la constitución económica del constituyente de Weimar, que revelaban el reconocimiento positivo de los principios inspiradores del Estado social (Neumann, 1983:138).

Sin embargo, y como sucederá en las constituciones de la segunda postguerra, los límites al intervencionismo público económico y a las funciones de redistribución serán los presupuestos de la economía de mercado y de la iniciativa de la propiedad privada. Un tipo de intervencionismo sustancialmente distinto del Estado socialista. De ahí que, la colectivización de la sociedad, como dinámica de reconciliación del derecho y la política, a través de la apertura del marco constitucional a la interacción entre política y economía, siguiendo las tesis de Bauer desarrolladas por Neumann y Sinzheimer entre otros, pretendía conciliarse con la pervivencia y garantía de las estructuras capitalistas (Neumann, 1987:38-42, Sinzheimer, 1982:61-62).

No obstante, los límites mencionados no implicaban una Constitución sin decisión en tanto incapaz de reorganizar de manera real y efectiva los desequilibrios entre poder político e intereses públicos. Como apunta Stolleis (2019:242), lo que unía a todas las tendencias, por encima de las diferencias partidarias, era un amplio consenso sobre la necesidad de que el Estado actuara de modo intervencionista. Ciertamente, la formación del consenso traducía la función de integración de la 
Constitución, lo que implicaba una ampliación del espacio confiado al conflicto, a la confrontación de fuerzas políticas, cuyo límite era la continuidad del sistema económico de la economía de mercado. Esta expresión jurídica del conflicto en el texto constitucional exteriorizaba esta disponibilidad a la dinámica social mediante la formulación más abierta de la Segunda Parte de la Constitución, la denominada Constitución social. Se definía en ella un espacio constitucionalmente reconocido a la iniciativa social y política que no podía desatender su función integradora, esencialmente los criterios de compatibilidad entre la economía de mercado y los fines sociales (Gusy, 2000: 606-608)

Por ello, la hegemonía de las fuerzas conservadoras en el desarrollo constitucional de la Constitución de Weimar no puede llevarnos a la conclusión de que esta fuera una Constitución sin decisión. La decisión político-jurídico fundamental existía, se basaba en un proyecto social que desplegaba sus efectos tanto en la primera como en la segunda parte de la Constitución (Stolleis, 2019: 234). Por lo tanto, sin desconocer el predominio de tales fuerzas, esto no significó una redefinición en la praxis política de la forma de Estado social, amparada en que los sujetos de la obra constituyente y quienes la implementaron en la práctica legislativa no representaban los intereses de clase en conflicto. El principio fundamental de colaboración entre el capital y el trabajo, asumido por el constituyente, acompañó a la eficacia del dispositivo constitucional en los primeros años de su entrada en vigor. Cuestión distinta es que los problemas que se derivaron entre la constitución de Weimar y la práctica política para su plena actuación constitucional, pusieran de relieve un desarrollo y aplicación desigual del propio dispositivo social. En todo caso, de la inactuación constitucional de estas disposiciones no cabe deducir una falta de correspondencia entre las exigencias de las nuevas estructuras sociales y las relaciones institucionales contempladas por el texto constitucional. La revitalización social de los principios declarados por la constituyente weimariana dependerá de la transformación de los agregados sociales, de unas fuerzas sociales que, como motor del pacto, activen un Estado social. Por lo tanto, la ausencia de estas será la que conduzca irremediablemente a una imposibilidad de dar cumplimiento a los compromisos constitucionales asumidos, desembocando en la inactuabilidad de la constitución.

Los acontecimientos que dinamitaron la complejidad de la estructura social weimariana, y que hicieron inviable el compromiso, tuvieron en el factor económico una causa determinante. Como advierte Mortati, tras la ruina de la clase media, provocada por la crisis financiera, los únicos protagonistas de la lucha política pasaron a ser los grandes empresarios y el proletariado que acusaba debilidades subjetivas, 
dado que solo hizo uso de su poder para alcanzar una serie de ventajas económicas inmediatas. De manera que, la posibilidad contemplada en la Constitución de introducir ciertas formas de socialización económica se hizo realidad en limitadas ocasiones (Mortati, 2019: 360). La desaparición de la escena política de las clases medias y el desgaste de la clase obrera, alcanzan en 1930 un punto de no retorno al compromiso constitucional de 1919. La profunda crisis estructural que sacudió el capitalismo en Alemania desde 1929 a 1933, debilitó hasta el extremo el orden social existente que había participado en la decisión fundamental organizada en torno al proyecto social weimariano. Y como reconoce Bauer, el “fascismo no ganó en el momento en que la burguesía estaba amenazada por la revolución proletaria, sino cuando el proletariado había sido debilitado y reducido a la defensiva mucho tiempo antes (...). Los capitalistas y grandes propietarios no confiaron el poder del Estado a los grupos fascistas para protegerse de una revolución proletaria amenazante, sino para reducir los salarios, destruir las conquistas de la clase obrera y eliminar los sindicatos y las posiciones de fuerza política ocupadas por la clase obrera; no para suprimir un socialismo revolucionario, sino para barrer las conquistas del socialismo reformista» (Mandel, 1988: 49).

\section{El constitucionalismo en la crisis del Estado social: la depuración de la normatividad} constitucional y su funcionalidad al nuevo orden de mercado europeo.

Al igual que sucediera en Weimar, en las Constituciones del pluralismo social de la segunda postguerra se impone la unificación de los ámbitos político y jurídico a través de una reconstrucción del fenómeno jurídico que asume como punto de partida la unidad de tales esferas. La necesidad de dar solución al conflicto social se impone tras la experiencia del fascismo y el fin de la segunda guerra mundial. Una necesidad que recupera el papel integrador de la constitución a través de la constitucionalización del conflicto social (Abendroth, 1986: 25).

La reiteración de los elementos centrales de las funciones asumidas por la actividad estatal en Weimar en los Estados sociales de la postguerra, permite reproducir lo ya observado a propósito de los espacios disponibles e indisponibles para el conflicto sancionados por la Constitución 1919. Economía de mercado y garantía de la iniciativa privada suponen que la actividad pública afectará al resultado del proceso productivo y no al propio proceso. Ambos límites actúan el momento de integración del capital en la Constitución. Por su parte, tampoco el capital puede comprometer los fines sociales que conectan 
con el gobierno público de la economía. Estos fines actúan el momento de la integración del trabajo. El gobierno público de la economía supone que no hay sumisión o subordinación al proceso de acumulación como sucedía en el Estado liberal. La posición del Estado en la forma de Estado social invierte la relación entre economía y política, evidenciando la posición del Estado social en el conflicto de clase, que es la referencia para la intervención pública en la economía. La Constitución del Estado social materializó plenamente sus contenidos durante los años 50 y 60 del siglo pasado, periodo que se manifestó en una contracción de la lógica del mercado, cuya actividad estaba ampliamente reglada por la intervención política pública en cuatro ámbitos principales: gestión coyuntural, política de la competencia y de precios, distribución de la renta y protección social (Adda, 1999:97-98).

Empero, la crisis del petróleo, unida a la inestabilidad y las tensiones monetarias internacionales de la década de los setenta, dejaron sentir sus efectos económicos y políticos en los textos fundamentales del Estado social. El repliegue gradual de las formas de economía pública y política fiscal funcionales a la distribución y creación de riqueza, y su sustitución, en la década de los 80, por un nuevo tipo de políticas públicas de contención del gasto público, anunciaban un nuevo orden jurídico y político que ya no podía realizarse sobre las bases materiales (pacto capital-trabajo) del Estado social. El conflicto social, su interiorización en el pacto constitucional, no tenía cabida en el nuevo orden, tampoco la función integradora de la Constitución del Estado social.

La revisión progresiva y regresiva del paradigma de la intervención pública en la economía, que se había consolidado en el constitucionalismo de la segunda posguerra, se concretó en torno a la necesidad de adoptar nuevas políticas económicas como respuesta a la crisis. Sus manifestaciones más evidentes se desarrollaban en las regulaciones legislativas y la praxis política, que actuaban como mecanismos de corrección de los elementos normativos constitucionalizados y propios de la forma de Estado Social. Ciertamente, se trataba de respuestas coyunturales y de urgencia, si bien la duración y consolidación de las mismas en el tiempo sugerían el comienzo de una nueva etapa, cuyo nuevo paradigma estaba entonces aún por consolidarse. Los procedimientos continuos de revisión interpretativa del enunciado constitucional del Estado social, como consecuencia del emergente contexto globalizador, materializaron el momento de crisis constitucional. La Constitución de la crisis vendría a expresar todas aquellas aportaciones doctrinales dirigidas a la interiorización, por el dictado constitucional, de una serie de elementos que reflejarían la revisión de los contenidos característicos del Estado social, en 
consonancia con las nuevas exigencias económicas y sociales de los procesos globales en curso. Los efectos de la debilidad normativa de la Constitución del Estado social, perturban el papel de integración de la constitución de la postguerra. La constitución no preside el ordenamiento interno, tan solo es una referencia primaria, pero desprovista de su papel prescriptivo para el sistema normativo.

La inactuación de la Constitución de la crisis cede el paso a la imposibilidad constitucional de la Constitución del Estado social. Fundamentalmente, porque ya no estaríamos en aquel momento de crisis donde las modificaciones responden a las necesidades coyunturales en juego, sin comprometer unos contenidos constitucionales que, simplemente, quedan faltos de cumplimiento provisional a la espera de que se recuperen las condiciones que los hagan posibles. Por el contrario, las reformas se corresponden o aparecen conectadas al momento de ruptura del Estado social, y evidencian, por lo tanto, la transición hacia un nuevo orden global caracterizado por las nuevas relaciones que se establecen entre la política y la economía.

La secuencia descrita, de la constitución de la crisis a la ruptura constitucional del Estado social, está estrechamente vinculada a la conexión existente entre el proceso globalizador y el proyecto europeo. En los comienzos del proyecto, la inicial yuxtaposición entre órdenes constitucionales en conflicto, el nacional, vinculado al Estado social, y el europeo, adscrito al constitucionalismo global de mercado, pronto se vio superada por las presiones del principio de integración del mercado, que imponía su lógica de legitimación del sistema. En los años 80, el activismo político de los órganos comunitarios se completaba con el comienzo de la aceleración de la integración de los mercados y la intensificación de las liberalizaciones en los mismos, antes sujetos a monopolios estatales, consolidando la institucionalización de la racionalidad económica en el espacio europeo (Maestro Buelga, 2007: 59-64). De hecho, la estrategia de la globalización financiera desprende sus efectos en el proyecto de integración, acelerando el avance de este último. Los nuevos principios organizativos, marcados por la estrategia de acumulación, se definen en torno a la unión monetaria y las políticas económicas disciplinantes. Éstas actúan, a su vez, como principios de legitimación de las nuevas políticas públicas condicionadas por la centralidad del mercado. El modelo de la UEM diseñado por Maastricht confirma la ruptura de la dinámica político institucional del Estado social. El gobierno débil, limita la capacidad de dirección económica de las orientaciones generales de la política económica. El control fuerte, política monetaria, 
materializa el momento del control fuerte como tutela-garantía de la centralidad del mercado (Maestro Buelga, 2006:87-94).

En este contexto, el mercado como principio organizativo se manifiesta en la definición normativa de los mecanismos para la realización del mercado interior y de los límites a la intervención pública en la economía (Walters y Haahr, 2004: 45-51). Circunstancia que permanece inalterada en las fases de crisis, 2010-2012, de la UEM. Desde esta perspectiva, tal crisis ha representado una evolución, que no ruptura, del orden de mercado europeo consistente en corregir las debilidades exhibidas por el momento del control fuerte durante la crisis del euro. De hecho, el dispositivo adoptado extra-muros del DUE obedece a la inmediatez de la respuesta, que requería una técnica procedimental alejada de las rigideces de los procedimientos legislativos de los Tratados, no a la novedad de las funciones. La función sigue siendo preservar la hegemonía de los criterios de la convergencia macroeconómica (estabilidad de precios, finanzas públicas saneadas y sostenibles, estabilidad del tipo de cambio y tipo de interés a largo plazo) vigentes desde Maastricht. Los EEMM y la Unión participan de esta unidad de la centralidad del mercado integrándose en su funcionamiento como un todo donde impera la homogeneidad contraria, eso sí, a la lógica interventora del gobierno de la economía del Estado social.

\section{La relación de subordinación del dispositivo social supranacional con la decisión de sistema del orden europeo y sus efectos}

La integración social supranacional acusa la lógica de la decisión de sistema y, en este sentido, se ve permeabilizada por sus principios directivos, que conforman una dimensión social contraria a la gestada por el Estado social. Por ello, no podemos hacer abstracción de la integración social sin contextualizarla en el marco de la centralidad del mercado como decisión fundamental del orden europeo. Esta circunstancia ha generado la caracterización del orden social europeo como un proceso de remercantilización de las dinámicas política y económica del sujeto constituyente del Estado social, el Trabajo, proceso que se ha manifestado desde los orígenes del proyecto, con los Tratados Constitutivos de las Comunidades Europeas, hasta el presente (Parker y Pye, 2018: 805-824). De ahí que consideremos que la constitución social sea una ficción en el DUE, desde el punto de vista jurídico y político. Con respecto a la perspectiva jurídica, porque la construcción del dispositivo social se traslada al ámbito del derecho derivado, con la consiguiente expulsión del espacio del Derecho Originario (los Tratados). Por 
lo tanto, nos encontraríamos con que el pretendido compromiso social supranacional no puede ser garantizado directamente por los mecanismos habilitados en los Tratados, y quedaría a merced de un juego de partidos políticos que lo reconducen a soluciones sin límites establecidos en torno a una convergencia mínima. Momento este último que manifestaría el punto de vista político. Como veremos, las fuerzas políticas presentes en los espacios institucionales de la Unión son representantes, de facto, de los particulares intereses nacionales. Intereses nacionales que, recordemos, no han cuestionado la decisión de sistema del orden europeo siquiera durante la crisis de la UEM. Por ende, tales partidos son proclives a dejar intacta en su estructura fundamental la centralidad del mercado, que solo permite el tanto de progreso social realizable a través de un principio organizativo de este tipo. Precisamente, en los siguientes apartados reflejaremos esta simetría armónica entre el principio organizativo del mercado único, los mecanismos para su concreción y el espacio socialmente realizable bajo sus coordenadas. El conjunto de partidos políticos e instituciones gestionan y dirigen al orden europeo en el sentido del poder global de mercado. De manera que, en este orden, el significado y valor del componente social estará condicionado por su funcionalidad a la garantía del principio organizativo.

\section{1. La expulsión de lo social del espacio constitucional de la Unión y su confinamiento al ámbito legislativo}

La nueva forma de articulación de las relaciones de poder entre la dimensión estatal y la dimensión económica en la Unión tiene su origen en una decisión política adoptada por los propios EEMM, principales protagonistas del proceso de integración. Esta realidad constitucional supranacional tiene como consecuencia directa que no podamos conferir al dispositivo social de la Unión la cualidad de parámetro legitimador de la intervención del poder público europeo en la economía. Por el contrario, el proceso de construcción, gestión y consolidación del proyecto de integración se caracteriza por la esterilización de todo límite social al mercado. El carácter de límites al capital que poseían los fines sociales en el Estado social desaparece; ahora su capacidad limitadora se transforma en su capacidad funcional para favorecer las dinámicas del mercado común. La integración del mercado como el núcleo regulador de la actividad económica de la Unión desarrolla sus propias políticas sociales en una orientación que, lejos de dirigirse a la corrección de las disfuncionalidades del mercado, supone la asignación de objetivos orientados a su garantía.

CEFD Número 43 (2020) I ISSN: 1138-9877 I https://doi.org/10.7203/CEFD.43.17458 
Las consecuencias de esta caracterización son dobles: por un lado, la imposibilidad de inferir o articular derechos para la ciudadanía de la Unión y obligaciones para los Estados en base a las disposiciones de naturaleza social de los Tratados. Su carácter programático los reconduce al ámbito de los objetivos y no de los derechos. Por otro lado, la subordinación al mercado define el sistema pretoriano de tutela de los contenidos sociales y evidencia la ruptura del momento de garantía, dotado de aquella capacidad de integración propia del constitucionalismo social (Olivier y Roth, 2004: 407-441).

La superioridad de los intereses homogéneos (libertades económicas, tutela de la competencia, moneda única, la unión económica), concretados en el modelo de la economía de mercado y de libre competencia, posibilita la confinación del ámbito de lo social al terreno político, ajeno a cualquier sujeción normativa. Fundamentalmente, porque el principio de legalidad de la Unión no busca conciliar los intereses en conflicto, como ocurre en el Estado social; su finalidad es impedir que, a través de las garantías formales establecidas por el ordenamiento europeo, cualquier intervención de los poderes públicos (supranacionales y/o nacionales) contrarreste a los principios fundamentales del derecho de la competencia y del mercado, cuyo carácter prescriptivo y fuerza material coincide, plenamente, con los contenidos formales de las disposiciones de los Tratados.

4. 2. La adhesión de las instituciones supranacionales a la decisión de sistema: especial referencia a los contenidos político-propositivos de la fase postcrisis del euro (2014-2019) y de

las elecciones a la IX Legislatura

El crecimiento exponencial de la desigualdad social entre los países de la zona del euro, con el que se saldó la gestión de la crisis de la UEM, introdujo en el debate institucional europeo desarrollado entre 2014 y 2019, e impulsado por la Comisión, la necesidad perentoria de reforzar la integración social. La consecución de la triple A social para Europa como objetivo indeclinable anunciado por la Comisión de Juncker, se materializó en el Paquete de Movilidad Laboral en 2016 ${ }^{4}$, y en el Pilar Europeo de Derechos Sociales $^{5}$ (PEDS) en 2017, acompañado, a su vez, del Paquete de Equidad Social ${ }^{6}$ de ese mismo año.

\footnotetext{
${ }^{4}$ Comunicación de la Comisión al Parlamento Europeo, al Consejo, al Comité Económico y Social Europeo y al Comité de las Regiones. Programa de trabajo de 2016. No es momento de dejar las cosas como están. Estrasburgo, 27 de octubre de 2015. COM (2015) 610 final.

${ }^{5}$ Documento disponible en el siguiente enlace: https:/ec.europa.eu/commission/sites/beta-political/files/social-summit-european-pillarsocial-rights-booklet_es.pdf (última consulta 24 de noviembre de 2020).

${ }^{6}$ Comunicación de la Comisión al Parlamento Europeo, al Consejo, al Comité Económico y Social Europeo y al Comité de las Regiones. Programa de trabajo de la Comisión para 2018. Estrasburgo, 24.10.2017. COM (2017) 650 final.
} 
A pesar de su pretendido potencial renovador de lo social, el conjunto de medidas continúa atribuyendo a la dimensión social una posición funcional a la preservación de la unidad del mercado interior y el fortalecimiento de la competitividad. En los programas de trabajo se reconoce el alma económica de la integración social, que no se configura como espacio de contención de los desequilibrios materiales del mercado, sino como funcional a las instancias productivas. También se aprecia en los documentos la dimensión extraeconómica de la propia integración económica, recurriendo a las técnicas de la regulación social pro mercado, consistentes en modificaciones en la redacción de la legislación sobre coordinación de los sistemas de seguridad social, condiciones de trabajo, y trabajadores transfronterizos en base a la prevención, detección y control de la competencia desleal entre operadores económicos.

Por su parte, el PEDS tampoco escapa de la formulación subalterna de la integración social requerida por la integración económica europea. La apuesta por una convergencia social de estándares pragmáticos al modelo de una economía de mercado abierta y de libre competencia, reproduciendo en el propio Preámbulo del Pilar las bases jurídicas que fundamentan la dependencia del desarrollo legal para la existencia como derechos de los distintos principios sociales, corrobora el espacio residual y subalterno que la integración económica reserva a la integración social en el mercado único (Pye, 2017: 567-589). En paralelo a las observaciones sobre los documentos propositivos y sus narrativas de la necesidad de una Europa más social, la breve aproximación al papel que las fuerzas políticas presentes en el espacio supranacional otorgan a la integración social, permite comprender el tanto de progreso realizable en este ámbito, dado que, como hemos advertido, la integración social tiene en el ámbito de la política a su principal y único ámbito de materialización. Nótese que estamos utilizando conscientemente la expresión partidos políticos en Europa, y no europeos. El motivo es la ausencia de verdaderas formaciones políticas supranacionales con capacidad para articular un programa común e integrado europeo, alejado de la propaganda electoral en clave nacional. Esta circunstancia, que intenta justificarse apelando a la diversidad de modelos sociales nacionales y las dificultades de un modelo de talla única, no es sino un pretexto para postergar un debate que no ha tenido su correspondiente paralelismo con relación a la UEM. La creación de una moneda única y su salvaguardia «a toda costa», no se ha visto pospuesta en el tiempo por las dificultades reales de políticas económicas y fiscales divergentes en el momento de su puesta en funcionamiento. Y cuando se ha solicitado el acceso al club del euro, los aspirantes han debido de cumplir con los criterios de convergencia nominal sin poder apelar a los importantes riesgos de cohesión social 
y económica generados por el ajuste de sus estructuras sociales internas a tales criterios. De forma que las exiguas concesiones a la integración social nada tienen que ver con las diversidades nacionales, y sí con salvaguardar al máximo la estructura fundamental del proyecto de integración.

En sintonía con esta apreciación, es interesante observar cómo las formulaciones sociales de los partidos políticos en Europa se realizan de tal modo que solo aspiran a un futuro indeterminado de colaboración en lo social, sin comprometer el principio organizativo del DUE. Al respecto, destaca el estudio sobre la concreción de la dimensión social en los programas electorales de las formaciones políticas en la Europa de la IX Legislatura (Pagano, Regazzoni, 2019). En él se distingue, dentro de los manifiestos partidistas, entre declaraciones normativas y propuestas políticas más elaboradas sobre políticas sociales en curso o que han sido objeto de discusión por las instituciones, analizando unas y otras en base a la dialéctica creación de mercado-corrección de mercado.

Del grueso de documentos políticos se destaca la preferencia del Grupo de la Alianza Progresista de Socialistas y Demócratas, junto con los Verdes, por medidas orientadas a la corrección del mercado. En todo caso, se aprecian diferencias sustanciales en cuanto al espacio territorial de implementación de mecanismos como la renta mínima, donde el referente político legislativo transita entre el centro (Europa), en el caso de los primeros, o la periferia (EEMM) en el caso de los segundos.

Por otro lado, liberales y populares priorizan el equilibrio dimensional positivo (integración social) y negativo (integración económica) en las políticas activas incardinadas en la estrategia de la flexiguridad. Esta estrategia está basada en fomentar la contratación, flexibilizando las garantías tradicionalmente vinculadas a los contratos de trabajo estándares, y trasladando los derechos laborales al mercado, a través de un intercambio de derechos y garantías por un incremento de las oportunidades de empleo. La necesaria dinamización del mercado de trabajo pasa por un necesario incremento de la competitividad empresarial, la cual facilitará las posibilidades de acceso al mercado laboral.

Con todo, se trataría de meros programas políticos cuya concreción debería esperar al resultado de las urnas para conocer la recomposición de fuerzas dominantes en el espectro político supranacional y su traducción al nuevo marco institucional. Cuestión esta última, en la que nos centraremos en el último de los apartados. 


\section{A modo de conclusión: del interregno de la centralidad del mercado a la transformación, como} reordenación, de las relaciones política-economía

La respuesta de la ciudadanía europea a la cita electoral para elegir la composición del Parlamento Europeo de mayo de 2019 fue continuista de convocatorias anteriores, al no producirse ningún sobresalto que pudiera alterar los tradicionales equilibrios entre populares, socialistas y liberales en el marco parlamentario. De modo que se mantiene la cohesión interna en cuanto a la viabilidad del proyecto de integración en sus actuales términos.

Confirma la adhesión de la regulación social funcional al mercado la agenda de trabajo de la nueva Comisión, presidida por Ursula von der Leyen, donde no se ofrece alternancia o alternativa de reformas en una dirección diferente a las realizadas hasta el momento. De hecho, en su discurso como candidata a la Presidencia de la Comisión ${ }^{7}$, en julio de 2019, ninguna de las dos medidas sociales que anunció representaban novedad alguna. Tanto el Sistema Europeo de Reaseguro de Desempleo, como el salario mínimo (página 6 del discurso), fueron acciones ya impulsadas, en 2014, por el entonces Comisario de Empleo, Asuntos Sociales e Inclusión, László Andor. Tampoco en lo relativo a los contenidos de las medidas se advierte nada nuevo. El reaseguro de desempleo tiene como objetivo combatir los shocks asimétricos que generan desigualdades entre los países miembros de la zona del euro, especialmente los afectados temporalmente por elevadas tasas de desempleo, pero no el desempleo estructural. En lo que respecta al salario mínimo, este se orienta a la lucha contra la competencia social desleal, pero no a combatir el fenómeno creciente de la pobreza laboral.

Lo que queremos poner de relieve es cómo las medidas plantean una integración social disfuncional con las funciones propias de una constitución social como dispositivo estabilizador y, por ello, corrector, de la jerarquía incondicionada de la integridad económica. No hay convivencia ni yuxtaposición entre las dinámicas de la integración social y la integración económica, sino subordinación y expulsión de la integración social de la decisión de sistema que la limita, en términos jurídicos, a una restricta legalidad. En definitiva, la legalidad social se presenta como obra de un poder público político e institucional que apuesta por conservar la estructura del sistema de mercado y sus coordenadas. Así

\footnotetext{
${ }^{7}$ Disponible en: https://ec.europa.eu/commission/sites/beta-political/files/opening-statement-plenary-session es.pdf (última consulta 25 de noviembre de 2020).
}

CEFD Número 43 (2020) I ISSN: 1138-9877 | https://doi.org/10.7203/CEFD.43.17458 
pues, la ausencia de una integración social con potencial renovador no puede ser atribuida a la diversidad de los sistemas nacionales o al desarreglo competencial en materia social, sino a la ausencia de procedimientos, de fuerzas políticas y de disposiciones jurídicas de derecho originario con capacidad para poner en práctica un ordenamiento supranacional europeo capaz de hacer realidad una nueva síntesis social donde el mercado no sea el centro de gravedad hegemónico.

No existe dimensión social europea como espacio corrector de los déficits del mercado. Existe, en todo caso, un espejismo o ilusión social exenta de toda lógica interventora. A ello habría que añadir que la crisis de la UEM no ha sido abordada en ningún caso desde la perspectiva de la ruptura y superación del modelo, sino desde la óptica de la introducción de medidas sociales dirigidas a amortiguar a corto plazo el malestar social de la crisis. El tiempo dirá si vivimos un interregno desordenado y volátil, como apunta Berman (2019), o si la próxima crisis conseguirá que lo constitucionalmente imposible devengue en, constitucionalmente inevitable bajo nuevas bases materiales de reordenación supranacional de las estructuras económico-sociales. Por lo pronto, aunque se imponen las cautelas, no consideramos que las medidas adoptadas a escala europea para hacer frente a los efectos del Covid-19 en las economías de la Unión ${ }^{8}$, estén generando una revisión, siquiera coyuntural, del escenario descrito a lo largo de estas páginas. Desde esta perspectiva, una panorámica general de las mencionadas medidas puede resumirse en la idea de una adhesión incondicional de las instituciones de la Unión a la disciplina de reforma de los mercados. Sólo así puede interpretarse el rechazo a políticas presupuestarias de alcance europeo, y a la mutualización total, y no parcial, de la deuda que generará la crisis pandémica ${ }^{9}$.

\footnotetext{
8 Respuesta económica coordinada al brote de Covid-19. COM (2020) 112 final. Disponible en: https://ec.europa.eu/info/sites/info/files/communication-coordinated-economic-response-covid19-march-2020_en.pdf (última consulta 25 de noviembre de 2020).

9 Resolución del Parlamento Europeo, de 17 de abril de 2020, sobre la acción coordinada de la Unión para luchar contra la pandemia de COVID-19 y sus consecuencias: https://www.europarl.europa.eu/doceo/document/TA-9-2020-0054 ES.pdf (última consulta 25 de noviembre de 2020).
} 


\section{Referencias bibliográficas}

ABENDROTH, W.; "El Estado de derecho democrático y social como proyecto político”, El Estado social. AAVV, Madrid, Centro de Estudios Constitucionales, 1986, p. 25.

ADDA, J.; La globalización de la economía: origen y desafios, Madrid, Sequitur, 1999, pp. 97-98.

ANDOR, L.; "Social dimension of the Economic and Monetary Union: what lessons to draw from the European elections?" Lecture at Hertie School of Governance, Berlin, 13 June 2014. Disponible en el siguiente enlance: http://europa.eu/rapid/press-release SPEECH-14-455 en.htm (última consulta 23 de noviembre de 2020).

ALLEMAND, F.; “More or less intergovernmental cooperation within the new EMU?" en L. Daniele, P. Simone, R. Cisotta. Democracy in the EMU in the aftermath of the crisis. Giappichelli \& Springer. 2017, p. 96.

ÁLVAREZ ÁLVAREZ, L.; "La Constitución de Weimar ¿una República sin republicanos?” Historia Constitucional, n 12, 2011, pp. 446, 450-451.

BERMAN, Sh.; "Interregnum or transformation? Social Europe, 2019. Disponible en el siguiente enlace: https://www.socialeurope.eu/author/sheri-berman (última consulta 23 de noviembre de 2020).

CAR, R.; “A reply to Sujit Choudhry's 'resisting democratic backsliding': Weimar legacy and self-enforcing constitutions in post-WWII left-wing constitutional theory”, Global Constitutionalism, Vol. 8, nº 2, 2019, p. 395.

CASTRO-CONDE, C.A., BOUZA, L.; "Nuevos enfoques teóricos en los análisis de la UE”, en: C.A. Castro-Conde, L. Bouza. Política de la Unión Europea. Crisis y continuidad. Centro de Investigaciones Sociológicas (CIS), 2019, p. 23.

DEMERTZIS, M., PISANI-FERRY, J., SAPIR, A., WIESER, Th.; "One size does not fit all: European integration by differentiation", Policy Brief, no. 3. 2018, pp. 3-8.

DUKES, R.; The Labour Constitution. The enduring idea of labour law, United Kingdom, Oxford University Press, 2014, p. $17-22$.

DE CABO, C. Contra el consenso: estudios sobre el Estado constitucional y el constitucionalismo del Estado social, México, Instituto de Investigaciones Jurídicas-UNAM, $390 \mathrm{pp}$.

GARCÍA HERRERA, M.A.; "Estado social y Estado económico”, Jueces para la democracia, nº 84, 2015, pp. 53-58.

GUSY, Ch.; "Las Constituciones de entreguerras en Europa Central”, Fundamentos. Cuadernos monográficos de teoría del Estado, derecho público e historia constitucional, nº 2, 2000, pp. 606-608.

JOERGES, Chr.; "What Is left of the European economic constitution II? From Pyrrhic Victory to Cannae Defeat, en P.F. Kjaer, N. Olsen. Critical Theories of Crisis in Europe. From Weimar to the euro. Rowman \& Littelfield International, London. 2016, pp. 149-150.

JELLINEK, W.; Teoría General del Estado, Buenos Aires, Albatros, 1978, pp. 9-13.

JELLINEK, W.; "El proceso de elaboración de la Constitución de Weimar”, en E. García, La Constitución de Weimar. La Constitución alemana de 11 de agosto de 2019. Tecnos, Madrid, 2019, p. 66.

HELLER, H.; “¿Estado de derecho o dictadura?” Escritos Políticos, Madrid, Alianza Universidad, 1985, pp. 283-285.

HELLER, H.; Teoría del Estado, México, Fondo de Cultura Económica, 1992, p. 19-39.

KJAER, P.F., OLSEN, N.; "European crises of public power from Weimar until today”, en P.F. Kjaer, N. Olsen. Critical Theories of Crisis in Europe. From Weimar to the euro. Rowman \& Littelfield International, London. 2016, p. xii.

MAESTRO BUELGA, G.; La Constitución del Trabajo en el Estado Social, Granada, Comares, 2002, 330 pp. 
MAESTRO BUELGA, G.; "El sistema de competencias en la constitución económica europea: Unión y Estados Miembros", Revista de Derecho Constitucional Europeo, no 6, 2006, pp. 65-99.

MAESTRO BUELGA, G.; "Estado mercado y constitución económica: algunas reflexiones sobre la crisis constitucional europea", Revista española de derecho comunitario europeo, $\mathrm{n}^{\circ}$ 8, 2007, pp. 59-64.

MANDEL, E.; El fascismo, Madrid, Akal, 1988, 72 pp.

MONTANI, G.; "From national to supranational: a paradigm shift in a political economy", en P. Iglesias Rodríguez, A. Triandafyllidou, R. Gropas. After the financial crisis. Shifting legal, economic and political paradigms, London, Palgrave Macmillan, 2016, pp. 126-128.

MORTATI, C.; "Note di diritto costituzionale comparato e di politica costituzionale comparata. Introduzione alla Costituzione di Weimar”, Raccolta di Scritti. Vol. IV. Giuffré. Milán. 1972, pp. 333.

MORTATI, C.; “Una valoración de conjunto sobre la experiencia de la Constitución de Weimar”, en E. García, $L a$ Constitución de Weimar. La Constitución alemana de 11 de agosto de 2019. Tecnos, Madrid, 2019, p. 360.

NEUMANN, F.; "The social significance of the basic laws in the Weimar Constitution", en O. Kirchheimer, F. Neumann, Social democracy and the rule of law, Allen \&Unwin, London, 1987, pp. 38-42.

NEUMANN, F.; "Il significato sociale dei diritti fondamentali nella Costituzione di Weimar", Il diritto del lavoro fra democrazia e dittatura, Bolonia, Il Mulino, 1983, p. 138.

NICOLAIDIS, K.; "The demoicratization of Eurozone Governance”, en S. Hennette, Th. Piketty, G. Sacriste, A. Vauchez, How to democratize Europe. Harvard University Press, Cambridge, London. 2019, pp. 104-105.

OLIVIER. P., ROTH, W.H.; "The internal market and the four freedoms”, Common Market Law Review, Vol. 41, nº 2, 2004, pp. 407-441.

PAGANO, G., REGAZZONI, P.; "The social dimension in the electoral programs of the European political groups". Disponible en el siguiente enlace: http://www.euvisions.eu/the-social-dimension-in-the-electoral-programs-of-the-europeanpolitical-groups/ (última consulta 23 de noviembre de 2020).

PARKER, O., PYE, R.; "Mobilising Social Rights in EU Economic Governance: A Pragmatic Challenge to Neoliberal Europe", Comparative European Politics, Vol. 16, n 5, 2018, pp. 805-824.

PRIEWE. J.; "Could Europe face the next recession?" Social Europe, 2019. Disponible en el siguiente enlace: https://www.socialeurope.eu/the-next-recession (última consulta 23 de noviembre de 2020).

PYE, R.; "The European Union and the absence of fundamental rights in the Eurozone: A critical perspective", European Journal of International Relations, Vol. 24, nº 3, 2017, pp. 567-589. https://doi.org/10.1177/1354066117703177.

RUNCIMAN, D.; “What Time Frame Makes Sense for thinking about Crises?” en P.F. Kjaer, N. Olsen. Critical Theories of Crisis in Europe. From Weimar to the euro. Rowman \& Littelfield International, London. 2016, p.8.

SACRISTE, G., VAUCHEZ, A.; "The Euroization of Europe: the extra-mural rise of the government of the Euro and the redefinition of the European project”, en S. Hennette, Th. Piketty, G. Sacriste, A. Vauchez, How to democratize Europe. Harvard University Press, Cambridge, London. 2019, pp. 10-38.

SCHMITT, C; Teoría de la Constitución, Madrid, Alianza Editorial, 1982, p. 137.

SINZHEIMER, H.; "La democratizzazione del rapporto di lavoro", en G. Arrigo, G. Vardaro, Laboratorio Weimar. Conflitti e diritto del lavoro nella germania prenazista, Lavoro. Roma. 1982, pp. 61-62. 
SINZHEIMER, H.; "La concreta organizzazione dei Consigli d'azienda”, en G. Arrigo, G. Vardaro, Laboratorio Weimar. Conflitti e diritto del lavoro nella germania prenazista, Lavoro. Roma. 1982, p. 49.

STARITA, M.; "Democratic principles and the economic branch of the European Monetary Union”, en L. Daniele, P. Simone, R. Cisotta. Democracy in the EMU in the aftermath of the crisis. Springer, Giapichelli, 2017, pp. 12-19.

STOLLEIS, M.; "El proyecto social de la Constitución de Weimar", Revista Historia Constitucional, nº 20, 2019, pp. 233 251.

THORNHILL, Ch.; "The constitutionalization of Labour Law and the crisis of national democracy”, en P.F. Kjaer, N. Olsen. Critical Theories of Crisis in Europe. From Weimar to the euro. Rowman \& Littelfield International, London, 2016, pp. 9596.

WALTERS, W., HAAHR, J.H.; Governing Europe. Discourse, Governmentability and European Integration. Routledge, London, 2004, $176 \mathrm{pp}$. 